\title{
Assessment of periodontal health status in psychiatric patients in and around Meerut city
}

\author{
Gazal Jain', Deepa D², Sandeep Chaudhary ${ }^{3}$
}

Post graduate student ${ }^{1}$, Professor ${ }^{2}$, Department of Periodontology, Subharti Dental College and Hospital, Meerut, U.P., India

Professor ${ }^{3}$, Department of Psychiatry, Subharti Medical College, Meerut, U.P., India

\begin{abstract}
:
Background: Mental illness affects people of all nations and at all economic levels. Psychiatric disorders affect the general behavior of a person, impair level of functioning, and alter perception. Psychiatric patients are one of the special groups requiring attention as they are often neglected because of ignorance, fear, stigma, misconception and negative attitudes. For psychiatric patients, periodontal health is a major determinant of general health and may have a low priority in the context of mental illness.
\end{abstract}

Objective: To assess periodontal health status in psychiatric patients in and around Meerut city.

Material and Methods: The study sample comprised of 100 psychiatric patients of Meerut city. Various socio-demographic variables like age, gender, parent's education, income were investigated. Dental examinations were done by measuring the following parameters of oral health: Simplified Oral Hygiene Index (OHI-S), plaque index (PI), gingival index (GI, bleeding on probing (BOP), pocket probing depth (PPD). The collected data was subjected to statistical analyses.

Results and Conclusion: The results of the study suggested poor oral hygiene due to neglected personal hygiene, compromised periodontal status and lack of motivation to get the dental treatment.

Keywords: Periodontal disease, psychiatric disease, oral hygiene, probing depth

\section{Introduction}

Oral health determines self-esteem as well as normal social interaction. Being an integral part of general health, it forms an important determinant for psychiatric patients. This is a special group of population as these patients are often neglected with their affected oral health. Impairment of the same leads to stress, depression and diminished quality of life. This may be owing to general self-negligence and poor oral hygiene in psychiatric patients due to lack of interest, low self-esteem, lack of knowledge to access dental services, fear of dental treatment, irregular attendance due to anxiety and inability to meet the cost, smoking (nicotine and cannabis), inadequate recall systems, practical difficulties during treatment sessions, socioeconomic status, underestimation of treatment need or pain, communication problems and bad co-operation. ${ }^{1-4}$

Chronic diseases are the result of long-term interactions

\section{Corresponding Author:}

Dr. Gazal Jain

PG Student, Dept. of Periodontology,

Subharti Dental College \& Hospital

Meerut, UP, India

Phone: +918393069491

Email: gazal.jain2441@gmail.com between a host and its environment and are multifactorial in nature. ${ }^{5}$ Periodontal disease is one of the most common causes of tooth loss. Stress, depression, and ineffective coping may contribute to the development of periodontitis. ${ }^{6}$ A number of mechanisms have been proposed, which could mediate the putative relationship between psychosocial conditions and inflammatory periodontal diseases. ${ }^{5}$ One model proposes that psychologic stress may result in immunologic and inflammatory responses that influence periodontal disease, whereas an alternative model hypothesizes that negative affective states may reduce compliance with preventive behaviors.

Considering the high prevalence of oral health problems in psychiatric patients, the present study was conducted to assess the oral health status in psychiatric patients attending the psychiatric outpatient department (OPD) and also those hospitalized in the psychiatry ward at Subharti Medical College and Hospital, Meerut, Uttar Pradesh.

\section{Materials and method:}

A cross-sectional survey was conducted in 100 psychiatric subjects, aged 20-60 years, attending the OPD and those 
who were hospitalized at psychiatric wards. Informed consent of the parents or guardians was obtained before the subjects were included in the study. The study was approved by the Ethical Committee for Research of the Subharti Dental College and Hospital, Meerut. Prior to the dental examination, demographic information was recorded for each subject: age, gender and education and income of parents. Clinical assessment of oral hygiene status was done with a mouth mirror and No. 23 explorer according to criteria of simplified oral hygiene index by Green and Vermilion. Clinical parameters like plaque index, gingival index, gingival bleeding index, pocket probing depth were also recorded. Probing depths (PDs) were measured using a William's graduated probe at four sites per tooth. Patients who were uncooperative and had systemic disorders like cardiac defects and with unknown etiology for mental disability were excluded from the study. Also patients who had undergone any periodontal treatment in last 1 year, or taking steroids (e.g., prednisone) and any other antibiotics in past 6 months were excluded.

The mean and standard deviation were used to describe the patterns of oral hygiene and periodontal status in all groups. Chi-square tests were used to test the differences in frequencies between the modes of brushing and occupation as well as between modes of brushing and different diagnostic groups. One-way Analysis of Variance (ANOVA) was used to test the differences in the mean scores of oral hygiene and periodontal indicators. Multiple linear stepwise regression analysis was employed to analyze the association of various socio-demographic and clinical variables with oral hygiene and periodontal indicators. Multiple logistic regression analysis was executed to test the associations of various independent variables with the oral hygiene and periodontal disease status. Statistical tests used were Percentage, Chi square test, ANOVA. Data were analyzed using the Stata statistical software, Version-13.0.

\section{Results}

20-30 year age group had highest proportion of study subjects and the mean age was 33.5 for study group. Female to male ratio was 1.5:1 for study group. Almost $2 / 3 r d$ patients in study group were married. More than $80 \%$ of study subjects belonged to either middle or lower socio-economic class. $37 \%$ of the patients used to brush once a day with the toothbrush and $25 \%$ of them never brushed while the rest of them used different modes of brushing (Graph 1, Pie charts-1, 2, 3)
It has been observed that depression (31\%) and bipolar affective disorder (BPAD) (14\%) were the top ranked diseases among psychiatry patients followed by substance abuse (12\%), obsessive compulsive disorder (11\%) and schizophrenia (11\%) while $21 \%$ of the patients were suffering from other psychiatric disorders. $76.7 \%$ of patients were suffering from psychiatric disease for more than 1 year. (Table 1, Pie chart 4)

The mean gingival bleeding index, simplified gingival index (GI-s), simplified oral hygiene index (OHI-s), plaque index and pocket depth score was found to be 62.4, 2.0, 4.0, 1.9 and 4.0 respectively (Graphs 2, 3, 4 and 5, Table 2) .

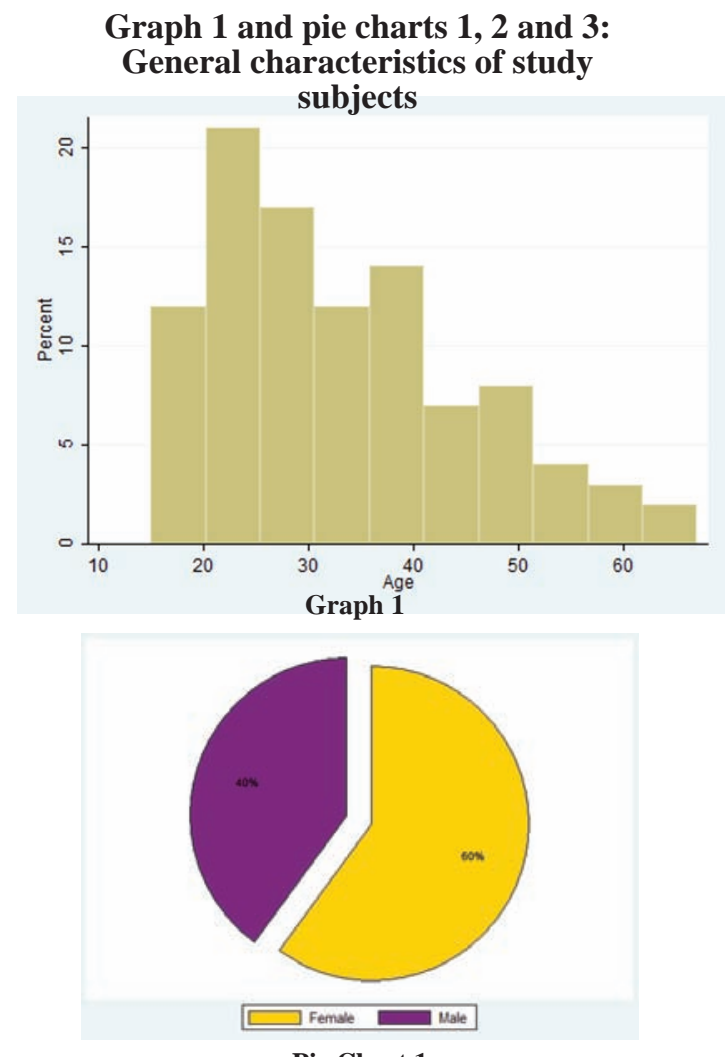

Pie Chart 1

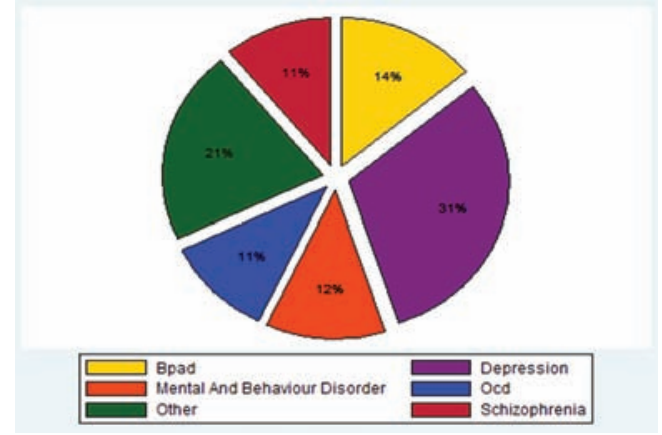

Pie Chart 2 


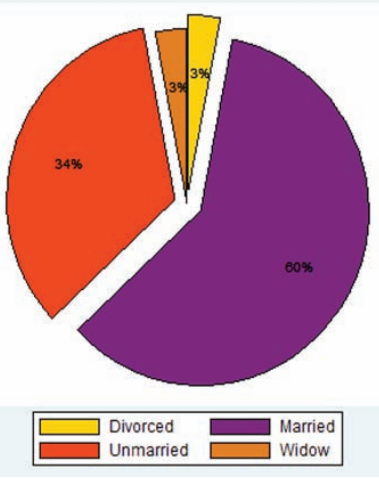

Pie Chart 3

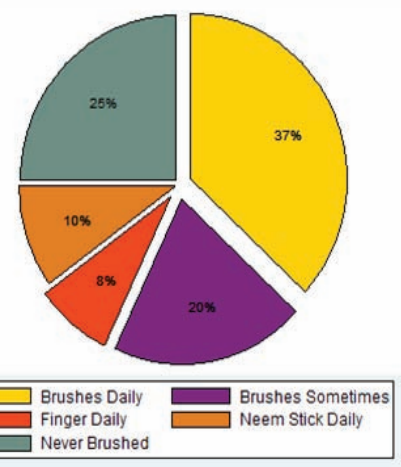

Pie Chart 4

Table 1 and pie chart 4: Medical variables in study group

\begin{tabular}{|c|c|c|}
\hline Diagnosis & Frequency & Percentage \\
\hline & & \\
\hline Bipolar Affective Disorder & 14 & 31 \\
\hline Depression & 31 & 12 \\
\hline Substance use & 12 & 11 \\
\hline Obsessive Compulsive Disorder & 11 & 21 \\
\hline Other & 21 & 11 \\
\hline Schizophrenia & 11 & 100 \\
\hline Total & 100 & \\
\hline
\end{tabular}

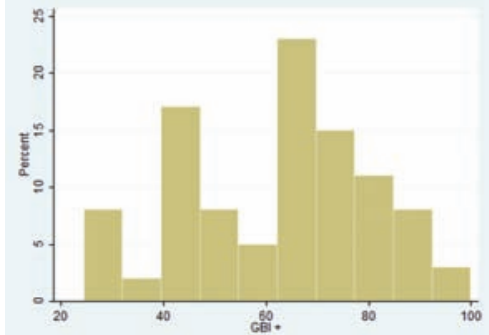

Graph 2: Gingival bleeding index in study subjects (GBI-positive scores)

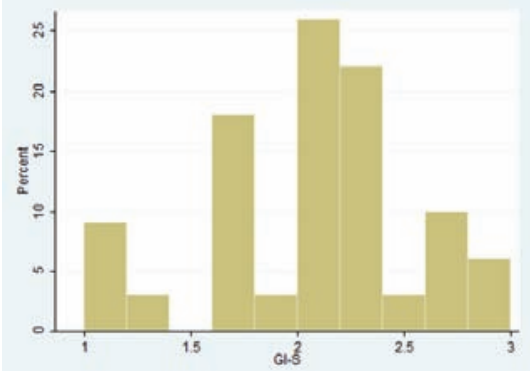

Graph 3:Simplified gingival index in study subjects (GI-S)

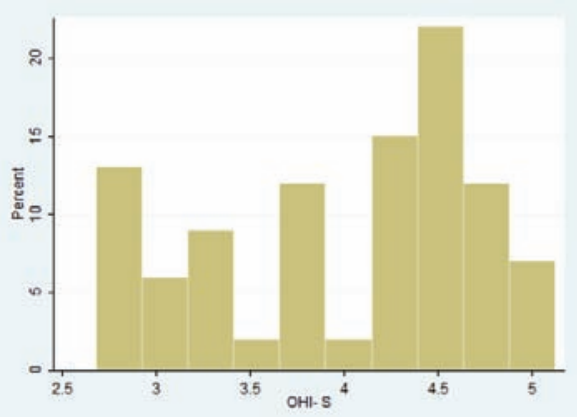

Graph 4: Simplified oral hygiene index in study subjects (OHI-S)

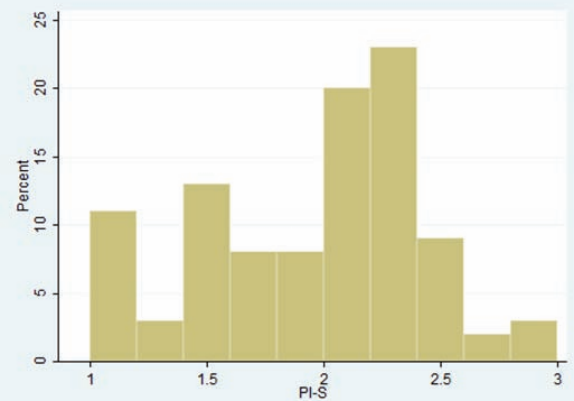

Graph 5: Plaque index in study subjects (PI)

Table 2

\begin{tabular}{|c|c|c|c|c|c|}
\hline Variable & Observations & Mean & $\begin{array}{c}\text { Standard } \\
\text { Deviation }\end{array}$ & Min & Max \\
\hline Age & 100 & 33.55 & 12.33487 & 15 & 67 \\
\hline OHI-S & 100 & 4.00985 & 0.7145538 & 2.7 & 5.1 \\
\hline PI-S & 100 & 1.922 & 0.4912543 & 1 & 3 \\
\hline GI-S & 100 & 2.0534 & 0.4966641 & 1 & 3 \\
\hline $\begin{array}{c}\text { Gingival Bleeding } \\
\text { Index }\end{array}$ & 100 & 62.4312 & 18.92697 & 25 & 100 \\
\hline Pocket Depth & 100 & 4.08221 & 0.8342182 & 2.3 & 6.3 \\
\hline
\end{tabular}

Graphs 2,3,4,5 and Table 2: Oral hygiene status of study group 
Table 3: Oral hygiene status among different variables of the study group

\begin{tabular}{|c|c|c|c|c|}
\hline Diagnosis & & Mean & $\begin{array}{l}\text { Standard } \\
\text { Deviation }\end{array}$ & Standard Error (mean) \\
\hline \multirow[t]{5}{*}{ Bipolar Affective disorder } & OHI-S & 3.783571 & 0.7661653 & 0.2047663 \\
\hline & PI-S & 1.743214 & 0.4698183 & 0.1255642 \\
\hline & GI-S & 1.895 & 0.4789853 & 0.1280142 \\
\hline & GBI & 51.13143 & 19.01685 & 5.082467 \\
\hline & $\mathrm{PD}$ & 3.885714 & 0.9149251 & 0.244524 \\
\hline \multirow[t]{5}{*}{ Depression } & OHI-S & 4.174355 & 0.6941623 & 0.1246752 \\
\hline & PI-S & 1.973548 & 0.4616532 & 0.0829154 \\
\hline & GI-S & 2.218065 & 0.4635761 & 0.0832607 \\
\hline & GBI & 65.64968 & 18.35334 & 3.296357 \\
\hline & $\mathrm{PD}$ & 4.041935 & 0.6308165 & 0.113298 \\
\hline \multirow[t]{5}{*}{ Substance use } & OHI-S & 4.118333 & 0.6650063 & 0.1919708 \\
\hline & PI-S & 1.9025 & 0.488339 & 0.1409713 \\
\hline & GI-S & 1.883333 & 0.6551798 & 0.1891341 \\
\hline & GBI & 62.34417 & 12.63465 & 3.647308 \\
\hline & $\mathrm{PD}$ & 4.153 & 0.7346977 & 0.212089 \\
\hline \multirow[t]{5}{*}{$\begin{array}{c}\begin{array}{c}\text { Obsessive Compulsive } \\
\text { disorder }\end{array} \\
\end{array}$} & OHI-S & 4.087273 & 0.7732023 & 0.2331293 \\
\hline & PI-S & 2.000455 & 0.5157153 & 0.155494 \\
\hline & GI-S & 1.987273 & 0.367997 & 0.1109553 \\
\hline & GBI & 63.53545 & 22.35905 & 6.741508 \\
\hline & $\mathrm{PD}$ & 4.227727 & 0.8813608 & 0.2657403 \\
\hline \multirow[t]{5}{*}{ Schizophrenia } & OHI-S & 4.166364 & 0.6527216 & 0.196803 \\
\hline & PI-S & 2.089091 & 0.5387663 & 0.1624441 \\
\hline & GI-S & 2.303636 & 0.3402432 & 0.1025872 \\
\hline & GBI & 68.56909 & 19.19127 & 5.786385 \\
\hline & PD & 4.194545 & 0.8038577 & 0.2423722 \\
\hline \multirow[t]{5}{*}{ Other } & OHI-S & 3.733333 & 0.697125 & 0.1521252 \\
\hline & PI-S & 1.847619 & 0.5204604 & 0.1135738 \\
\hline & GI-S & 1.916667 & 0.5044337 & 0.1100765 \\
\hline & GBI & 61.46952 & 19.57522 & 4.271662 \\
\hline & PD & 4.097143 & 1.115375 & 0.2433948 \\
\hline
\end{tabular}

\section{Discussion}

Mental illness is the clinically recognizable pattern of psychological symptoms or behavior causing acute or chronic ill health, personal distress or others. ${ }^{8}$ Mental disorders are common with more than one in three people in most countries reporting sufficient criteria for at least one diagnosis at some point in their life, and actual life time prevalence rate for mental disorder is estimated to be between $65 \%$ and $85 \% .{ }^{9}$ It has been reported that $74 \%$ of adults have daily performances affected due to oral health. ${ }^{10}$ Like healthy individuals, those with disabilities deserve the same opportunities for dental services as quality oral health care contribute to holistic health, which should be a right rather than a privilege.

The present study was conducted to assess the periodontal health status of psychiatric patients in and around Meerut city in the context of scant attention for the correlation between psychiatric conditions and dental diseases (Table 3). Evidences have shown that patients suffering from mental illnesses are more vulnerable to dental neglect and poor health. ${ }^{11,12}$ The results of our study were in accordance with the above mentioned studies and demonstrated that there was a high demand for provision of dental services, especially to the disabled, and that this population had received less dental treatment. General characteristics of study subjects in our studies showed that highest proportion of study subjects was in the age group of 20-30 years with a mean age of 33.5 years. Female to male ratio in our study was $1.96: 1,60 \%$ of patients were married and more than $80 \%$ belonged to middle or lower 
socio-economic class. Tang et $\mathrm{al}^{13}$ in their study reported $64.8 \%$ of subjects were males with a mean age of 44.1 years, while according to a study by Mirza et al ${ }^{14}$ the mean age was 39 years with male to female ratio of 1.4:1.5. Also in a study by Ramon et al ${ }^{15}$ the mean age was 54 with male to female ratio of 1.38:1, while Manish et $\mathrm{al}^{16}$ in their study of oral health and treatment needs in institutionalized patients in Davangere city in Karnataka reported that the highest proportion of patients was in 15-24 age group i.e $25 \%$, proportion of males was $58.3 \%$ and male to female ratio was 1.56:1. These results were consistent with the results of our study.

Data on medical variables showed that depression (31\%) and bipolar affective disorder (BPAD) (14\%) were the top ranked diseases among psychiatry patients followed by substance abuse (12\%), obsessive compulsive disorder (11\%) and schizophrenia (11\%) while $21 \%$ of the patients were suffering from other psychiatric disorders. $76.7 \%$ of patients were suffering from psychiatric disease for more than 1 year. Shukla and Shrivastava in their study reported the patients with anxiety disorders were highest and mood disorders on second although proportion of patients was low i.e. 19 and $10 \% .{ }^{17}$ Manish et al had similar findings, they reported that $45 \%$ of patients were suffering from mood disorders followed by schizophrenia (25\%) and psychoactive substance use disorders (20.6\%). ${ }^{16}$

From above findings, it is clear that oral health is affected in psychiatric patients. Advanced oral diseases are often developed in chronic psychiatric disorders like schizophrenia and BPAD because of multiple factors like life style changes, decreased family supports, lack of insight for general health, and diminished attitude of health professional towards oral health status. ${ }^{3}$ Schizophrenic patients have increased incidence of caries and periodontal diseases due to the antipsychotic medications, which usually have anti cholinergic side effects leading to xerostomia. In addition, these patients have risk of developing tardive dyskinesia, which are repetitive purposeless involuntary movement and affects the oral cavity. ${ }^{18,19}$

A recent systematic review of case-control, cross-sectional studies examining psychologic factors and periodontal disease indicated that $57.1 \%$ of the studies reported a positive correlation between stress or other psychologic factors and periodontal disease, and $14.2 \%$ did not. Therefore, the weight of the evidence seems to suggest an association between psychologic distress and periodontal health. ${ }^{20}$ However, further studies to establish the association of periodontal disease in psychiatric patients are recommended.

\section{Conclusion}

Oral health is an integral and important part of health care. Patients suffering from psychiatric disorders experienced poor oral health, required periodontal treatment. Thus, more number of long term longitudinal studies analyzing the association between periodontal status and psychiatric diseases are recommended.

\section{References}

1. Jyoti B, Muneeshwar PD, Srivastava R, Singh AR, Kiran M, Simlai J. Oral health status and treatment needs of psychiatry inpatients in Ranchi, India. J Ind Acad Oral Med Rad. 2012;24(3):177-181.

2. Shah VR, Jain P, Patel N. Oral health of psychiatric patients: A cross-sectional comparison study. Dent Res J (Isfahan). 2012;9(2):209-14.

3. Mushtaq R, Shoib S, Singh R, Iqbal U, Shah T, Mushtaq $\mathrm{S}$ et al. Is institutionalization a risk factor for poor oral health? - A comparison of the oral status of schizophrenia and bipolar affective disorders. Int J Res Med Sci. 2014;2(2):580-584.

4. Jain M, Mathur A, Sawla L, Choudhary G, Kabra K, Duraiswamy $\mathrm{P}$ et al. Oral health status of mentally disabled subjects in India. $\mathrm{J}$ Oral Sci. 2009;51(3):333-40.

5. Goyal S, Gupta G, Thomas B, Bhat KM, Bhat GS. Stress and periodontal disease: The link and logic!! Ind Psychiatry J. 2013;22(1):4-11.

6. Bindushree A R, Ranganth V, Nichani AS, Naik R. Evaluation of the association between stress, depression and periodontitis - A clinic-biochemical study. Int J Biol Med Res. 2013; 4(1): 2884-2888.

7. Genco RJ, Ho AW, Kopman J, Grossi SG, Dunford RG, Tedesco LA. Models to evaluate the role of stress in periodontal disease. Ann Periodont 1998;3:288-302.

8. World Health Organization International classification of mental and behavior disorder, Diagnostic criteria for research, ICD, 10th ed. Geneva: World Health Organization; 1993.

9. Cross-national comparison of the prevalence and correlates of mental disorders. WHO International Consortium in Psychiatric Epidemiology. Bull World Health Organ. 2000;7:413-26.

10.Adulyanon S, Vourapukjaru J, Sheiham A. Oral impacts affecting daily performance in a low disease Thai population. Community Dent Oral Epidemiol. 1996;24:385-9. 
11.Stiefel DJ. Edmond Truelove. The role of rehabilitation dentistry. (Good oral health and hygiene for people with disability contributes to rehabilitation). American Rehabilitation. U.S. Rehabilitation Services Administration. 1990. High Beam Research. Available from: http://www.highbeam.com [Last accessed on 2011 Dec 14].

12.Armstrong. Dentist and community care. Br Dent J. 1994;176:48-9.

13.Tang WK, sun FCS, ungvari GS, O’donell D. Oral Health of Psychiatric in patients in Hong Kong. Int J Soc Psychiatry. 2004;50:186-91.

14. Mirza I, Day R, Phelan M, Sulff-Cochrane V. Oral health of psychiatric in patients- A point prevalence survey of intercityhospital. Psychiatr Bull 2001;25:143-5.

15.Ramon T, Grinshpoon A, Zusman SP, Weizman A. Oral health and treatment needs of institutionalized chronic psychiatric patients in Israel. Eur J Psychiatry. 2003;18:101-5.

16. Kumar M, Chandu GN, Shafiulla MD. Oral health status and treatment needs in institutionalized psychiatric patients: One year descriptive cross sectional study. Indian J Dent Res. 2006;17:171-7.
17.Shukla GD, Shrivastava RP. A psychiatric study of cases attending dental OPD of a teaching general hospital, Jhansi. Indian J Psychiatry. 1983;25:198-202.

18.Southern Association of Institutional Dentists. Module 9: clinical concerns in dental care for persons with mental illness, 2001. Available at: http://saiddent.org/modules/17_module9.pdf. Accessed 13 June 2006.

19. Clark DB. Dental care for the psychiatric patient: Chronic schizophrenia. J Can Dent Assoc. 1992 Nov;58(11):912.

20.Peruzzo DC, Benatti BB, Ambrosano GMB, Noqueira-Filho GR, Sallum EA, Casati MZ et al. A systematic review of stress and psychologic factors as possible risk factors for periodontal disease. J Periodontol. 2007;78:1491-1504.

How to cite this article:

Gazal J, Deepa D, Sandeep C. Assessment of periodontal health status in psychiatric patients in and around Meerut city. CODS J Dent 2014;6;72-77

Source of support: Nil. Conflict of interest: None Declared. 